\title{
Preliminary Radar Climatology of Central Pennsylvania
}

\author{
Joel N. Myers \\ Pennsylania State University
}

(Manuscript received 21 November 1963, in revised form 27 January 1964)

ABSTRACT

\begin{abstract}
Grid analysis of radar films at one hour intervals over two convective seasons was performed to assess the role of the synoptic situation and local topography on the pattern of showers in central Pennsylvania. Diurnal variations in extent and distribution of echoes are traceable to air motions that result from the nature of the local topography.

Correlations between synoptic variables and the amount and nature of showers show that surface dewpoint depression is the best indicator of scope coverage as well as size and development of showers. It was also found that the superimposition of a favorable vertical motion field on a region of convective precipitation allows showers and squall lines to undergo greater development.
\end{abstract}

\section{Introduction}

The literature contains many reports dealing with the characteristics of individual echoes and groups of echoes in regions of widely differing terrain, including central Pennsylvania. Several investigators have used radar to study the effect of the topography on the generation, growth, movement and duration of showers. On the other hand, there have been only a few studies concerned with diumal variations in the amount and distribution of echoes and still fewer attempts at relating radar information to synoptic-scale motions and patterns. Investigations in these latter areas should prove quite fruitful to short range forecasting particularly in regions of non-uniform terrain. Also, the development of a realistic physical model that is capable of explaining the extent and distribution of echoes at a given time in a certain region may be as depencient on the radar climatology as on the properties of individual echoes. It was for these reasons that this study was undertaken.

Specifically, this investigation was concerned with:

1) Evaluating the effects of topography on the pattern of precipitation in central Pennsylvania;

2) Determining the diurnal variations in the amount and distribution of echoes;

3) Relating the moisture content, wind field and other synoptic variables to the distribution, size, pattern and lateral extent of convective precipitation echoes.

\section{Topography of central Pennsylvania}

The topography of central Pennsylvania (shown in Fig. 1) is almost ideal for the study of terrain-related convective phenomena. The area is divided into two distinct topographic types by a sharp southeast-facing escarpment along the Allegheny Mountains.
The Allegheny Plateau section, which is the region northwest of the Allegheny Mountains, has an average elevation of $2000 \mathrm{ft}$ but displays local relief of 300 to 500 $\mathrm{ft}$. To the southeast of the Allegheny Mountains is the Appalachian Ridge and Valley section, which is characterized by parallel ridges and intervening valleys that are oriented northeast-southwest. These valleys vary in width from 1 to $10 \mathrm{mi}$ and some of them extend almost without break and with fairly uniform height for 25 to $100 \mathrm{mi}$. The ridges are sharp, and they stand between 1600 and $2400 \mathrm{ft}$ above sea level and from 500 to $1500 \mathrm{ft}$ above the adjacent valley floors. The convergence of

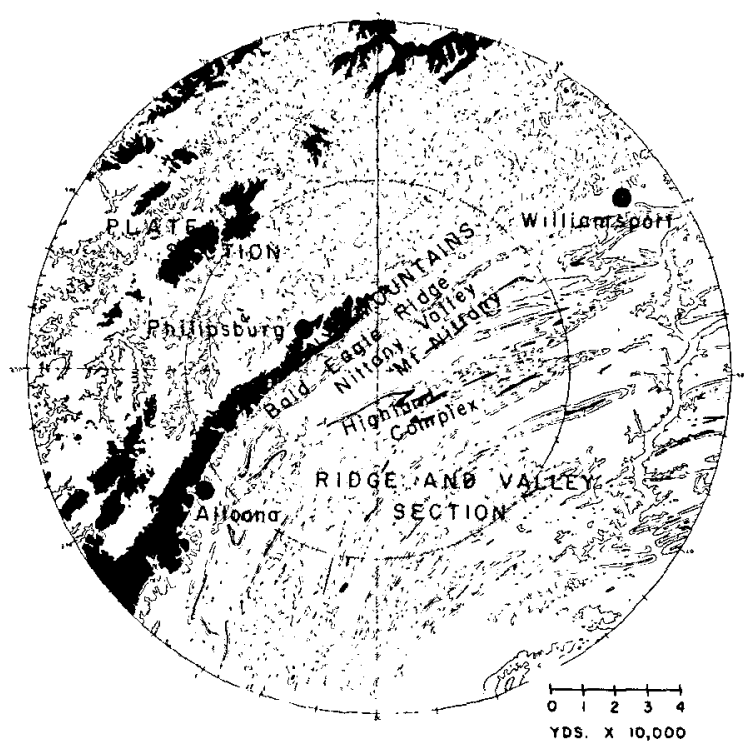

FIg. 1. Topographic map of radar coverage area (Contours every $500 \mathrm{ft}$; solid area greater than $2000 \mathrm{ft}$. Inner circle $34 \mathrm{mi}$, outer circle $63 \mathrm{mi}$ ). 
three ridges in an area several miles southeast of the radar site forms what will be called a highland complex, a comparatively large region of elevated terrain.

\section{Radar and synoptic data}

A 9.1-cm acquisition radar, which is part of the $M 33 \mathrm{C}$ radar system that is located at University Park, Pa., was used to observe precipitation-produced echoes. It is operated with an antenna elevation angle of $4 \mathrm{deg}$ and a range presentation of $68 \mathrm{mi}$. The ground clutter with this setting is shown in Fig. 2. The PPI scope was photographed with a $16-\mathrm{mm}$ movie camera almost continuously between 0830 and $2300 \mathrm{EST}$ during the convective seasons of 1960 and 1961. The films were analyzed by employing a grid consisting of square meshes whose dimensions of three-eighths of an inch are equivalent to 6 mi. Each mesh was regarded as empty if less than 3 per cent filled with precipitation echoes, as one quarter covered (denoted by " 1 " on the grid) if less than 50 per cent filled, and as three-quarters covered (denoted by a " 3 ") if coverage was 50 per cent or more. This system of classification was chosen after consideration was given to limitations in signal resolution, the relatively fine mesh size and difficulties in discriminating between precipitation-caused echoes, ground clutter and echoes due to aircraft and birds.

A comparison of the cross-sectional area of echoes as obtained by the grid approach and direct planimeter measurement for a variety of echo patterns indicates that results obtained by the grid method are sufficiently accurate for the purposes of this study.

Special care was taken to differentiate precipitation echoes from ground clutter and, where possible, "angels." To guarantee the reliability of echo dimension estimates within the area of ground clutter, echoes were traced backward and forward from the place of observation. The analyses of convective situations are probably quite accurate, but the reliability of analyses made during periods of stratiform precipitation are questionable. Fortunately, the overwhelming majority of cases are convective in nature.

Since 712 hours of data were available when the analysis was begun, it was decided that more representative results could be obtained from analyzing all of the data at one-hour intervals than from studying a portion of it over some shorter time increment. Furthermore, since regular airways weather observations are made once an hour, each analyzed grid corresponds to a surface map analysis. Surface synoptic variables were obtained by averaging reported values of conditions at airways weather stations in central Pennsylvania.

Observed or computed values of Showalter Stability Index, precipitable water, NWP vertical velocity, 500$\mathrm{mb}$ vorticity and $850-\mathrm{mb}$ relative humidity at Pittsburgh, $\mathrm{Pa}$., for 00 GMT and 12 GMT were taken from facsimile charts and teletype reports. They were interpolated to give values corresponding to the times of grid

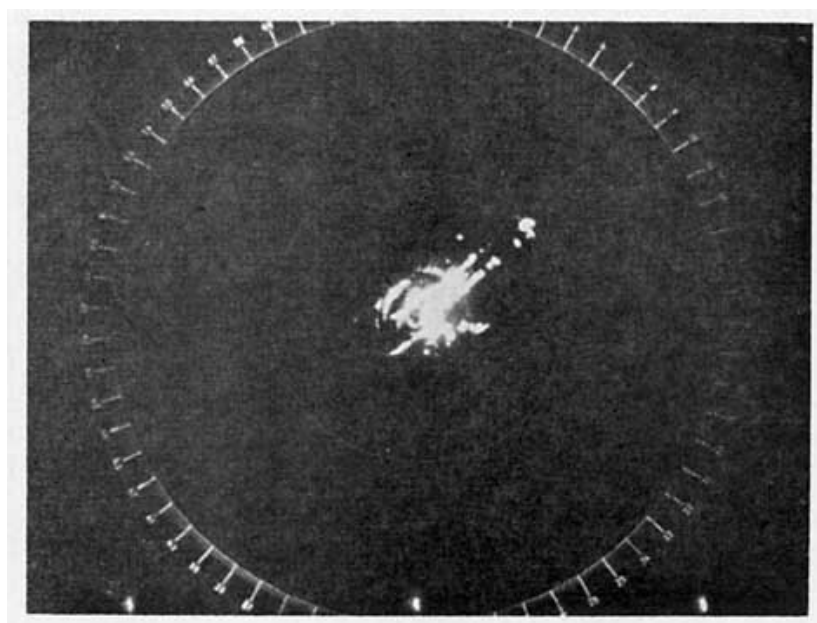

FIG, 2. Ground clutter at an anterna elevation of $4 \mathrm{deg}$. (Range circle at $31 \mathrm{mi}$ ).

analysis. The 850-500-mb wind shear was computed for Pittsburgh from 00 GMT and 12 GM'T radiosonde reports, and the results were also interpolated to yield hourly values.

Both the radar and synoptic data were punched onto IBM cards and an IBM 7074 digital computer was used to calculate mean echo patterns and the amount of the scope covered with echoes for ea:h analysis.

\section{Quantitative description of echo patterns}

The discovery of relationshijss between PPI scope appearance and the state of th: atmosphere as represented by synoptic parameters could provide meteorologists with valuable inforrnation concerning the physics of precipitation and the processes by which the topography and landscape worl: to promote or inhibit convection. Such knowledge can serve as the basis for a mesoscale precipitation model for the area of study.

Before such relationships cov.ld be uncovered, however, it was necessary to derive methods of describing the horizontal size, shape and pattern of convective echoes. The method of grid analysis used in this study lends itself to the computation of several quantitative systems that describe the characteristics of scope appearance and the properties of 1?PI echoes. Experimentation with several of them led " 0 the adoption of three for detailed study.

The coefficient of localized scatter is a measure of the scatter of showers in the area of precipitation. It is computed by dividing the number of ones by the total number of ones and threes on the grid. When most of the numbers are threes this coffficient is small and the echoes tend to be solid and well-defined. At the other extreme, when the coefficient of localized scatter is near one, the echoes are small, probajly ill-defined and weak.

The coeffcient of contiguity is a measure of the size of convective cells and squall lires. It is calculated by 
dividing Associated Threes by five times the number of threes on the grid.

To determine Associated Threes, it is necessary to consider each square on the grid individually. If there is a three in a mesh, the four bordering squares are scanned for threes. The number of threes in these five meshes is tabulated and then the process is repeated until all squares have been considered. The total number of threes obtained in this manner is termed Associated Threes.

The coefficient of contiguity is small when no prominent echoes exist and it increases by a geometric progression as convective cells or squall lines become larger.

The scope scalter coefficient is a measure of the scatter of convective echoes. It has low values when echoes appear to be highly organized and high values when echoes are far apart and in random order. This parameter is computed by dividing the number of ones and threes by Associated Ones and Threes. To compute Associated Ones and Threes the process for computing Associated Threes is repeated but this time both ones and threes are considered to be threes.

\section{Limitations of radar observations}

With allowance for normal atmospheric refraction of microwaves and the curvature of the earth, the half power points at maximum range are at 15,100 and 40,700 feet. A precipitation rate of $10 \mathrm{~mm}$ per hour (drop-size distribution according to Laws and Parsons, 1943) will be detectable at maximum range provided at least 14.8 per cent of the beam is filled; therefore, showers of this intensity must extend to $20,600 \mathrm{ft}$ to give echoes. Showers with precipitation rates of $3.0 \mathrm{~mm}$ per hour must fill 85 per cent of the beam, which corresponds to an altitude of $35,400 \mathrm{ft}$, to be detected at $68 \mathrm{mi}$.

Of 850 warm and cold frontal echoes studied by Mather (1949) only 14 had tops extending beyond $22,500 \mathrm{ft}$ and only 44 reached above $18,500 \mathrm{ft}$. Battan and Braham (1956) observed 57 cumulus clouds over the central United States that contained precipitation echoes. Only 7 were observed to have tops in excess of $24,000 \mathrm{ft}$ and 23 were taller than $20,000 \mathrm{ft}$. These findings indicate the percentage of convective echoes detected with the radar setting used in this investigation should decrease steadily with distance from the antenna at moderate and long ranges, and only a small fraction of the showers at maximum range will intercept sufficient power to produce visible echoes. This effect greatly overshadows any artificial enlargement of echoes that might result from the finite cross section of the radar beam.

\section{Mean echo pattern}

The mean areal distribution of precipitation echoes for 712 grids between May and September appears in Fig. 3. The frequency of echo occurrence decreases almost linearly with increasing distance from the center of the scope at moderate and long ranges. This pattern is obviously not representative of the true distribution of precipitation, but rather implies the seriousness of the radar's failure to detect echoes in the outer portion of the coverage area. These results are in agreement with those of Beckwith (1958) and Austin (1957).

The interception and absorption of power by near-by mountains tend to create "echo shadows" which appear as areas of relatively low echo occurrence that extend from just beyond the mountains to the edge of the scope. This effect is most pronounced for Nittany Mountain. Another shadow caused by the cluster of trees south of the antenna is cast across most of the southern half of the scope and obscures nearly all wouldbe echoes in the extreme south. A shadow from a water tower southwest of the radar is also in evidence.

These effects-particularly the radar's inability to detect a large percentage of echoes at moderate and long ranges because most of the radar energy was overshooting would-be targets-fix an upper limit on the amount of scope coverage. Of all cases studied, the coverage never exceeded 35.7 per cent, and in only one per cent of the cases did the coverage exceed 30.0 per cent.

To eliminate the systematic decrease of echo occurrence at moderate and long ranges the distribution of echoes was range normalized. This was accomplished by the following procedure:

Taking the echo frequency at each mesh to be at the square center, frequencies were averaged around the scope center in circular strips, 6 miles wide. These values were smoothed, and since it is assumed the probability of detecting precipitation is not a function of range at

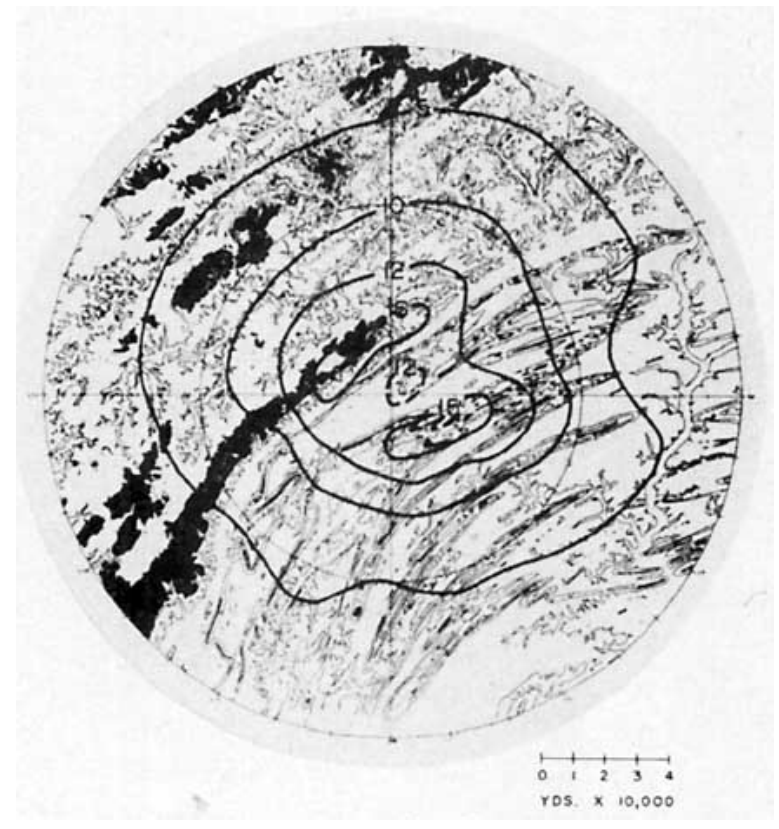

FIG. 3. Mean echo coverage (in per cent) for period May to September (712 cases). 
short ranges, the highest strip value was assigned to the region between that strip and the scope center. Next, the mean echo frequency of each grid point was obtained by interpolat ing between the smoothed strip values according to the distance of the grid points from the center. Finally, the actual echo frequency for each square was divided by the corresponding mean echo frequency.

One unfortunate characteristic of this procedure is its tendency to change the intensity of anomalies. For example, if two maxima occur at the same range both will be weakened because the mean echo occurrence at that range will be greater than it would have been with only one maximum present, other things being equal.

\section{Diurnal variations}

Since the radar was nearly always operated between 0845 and 2245 EST when showers were in the vicinity the number of cases for each hour is in itself a rough indicator of the diurnal variation of precipitation. A plotting of mean and median scope coverages versus time is shown in Fig. 4. Since the distribution of scope coverage is highly skewed in a positive sense, the median scope coverage is more sensitive to convective activity than the mean. The number of cases and the median scope coverage for each hour were multiplied together to yield a weighted median. A plot of this parameter versus time appears in Fig. 5.

The most outstanding feature of the diurnal precipitation variation, as represented by this last curve, is the maximum at about $1500 \mathrm{EST}$, which is undoubtedly due to the increase in convective activity that accompanies solar heating. Besides the afternoon maximum there are two less prominent but clearly evident maxima; one is at $1045 \mathrm{EST}$ and the other is in the evening. Before a possible explanation of these maxima is postulated, it will be necessary to examine the diurnal variations in the areal distribution of convective echoes. This will be done in the next section.

Notice that for equal time increments from the peak of precipitation, there is generally more activity in the later hours than the earlier ones. Showers may not form until the atmosphere is rendered unstable by insolation,

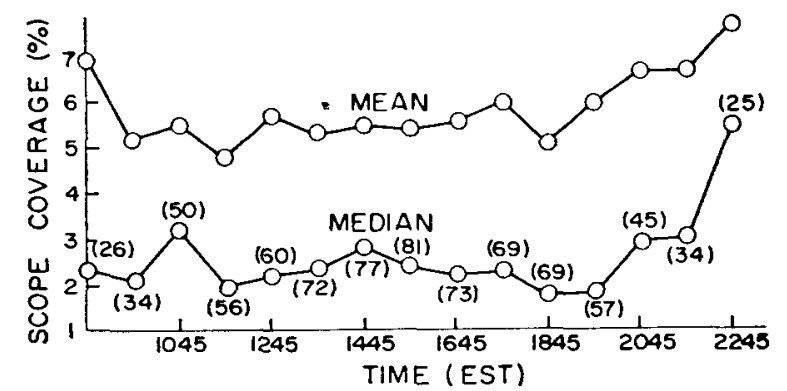

FIG. 4. Graphical representation of mean and median scope coverage as a function of time. Number of cases is in parenthesis. but once this level of instability has been achieved convection is slow to dissipate.

\section{Areal distribution}

The mean range normalized pattern of echoes (Fig. 6) is similar to the precipitation climatology of the area, at least for short ranges. This implies the intensity of precipitation, on the average, is si nilar throughout the coverage area and anomalies are due to the greater or lesser occurrence of precipitation : n certain regions.

Hosler, Davis and Booker ${ }^{1}$ discovered that some areas are three times as likely to hav 2 a shower form over them as other areas. Anomalies of similar magnitudes were found for shower dissipation:;. Since the developing and dissipating showers they studied occupied a very small area of the scope, it is concluded that the topography exerts a greater influence on the formation and dissipation of individual showers than on the precipitation pattern as a whole.

Mean range-normalized echo distributions, smoothed in both time and space, at one hcur intervals from 0945 to $1345 \mathrm{EST}$, are given in Figs. 7 through 11. Because of the great variability of echo occurrence in the outer portion of the scope, only data within the first 25 or 30 mi should be considered in detail. Also, it should be realized that the whole pattern will be characterized by considerable random variations in the early morning and late evening because of the small size of the data samples.

The pattern at 0945 EST shows the average occurrence of echoes to be 20 to 30 Fer cent more frequent over the Allegheny Plateau and the highland complex than in the Nittany Valley. This differential increases to almost 50 per cent during th 2 next hour. A similar

\footnotetext{
${ }^{1}$ Hosler, C. L., L. G. Davis and R. D. Booker, 1962: The role of orographic barriers of less than $300 \mathrm{C}$ feet in the generation and propagation of showers. Report on NSF G-7363, Penn. State Univ., Univ. Park, Pa., 157 pp.
}

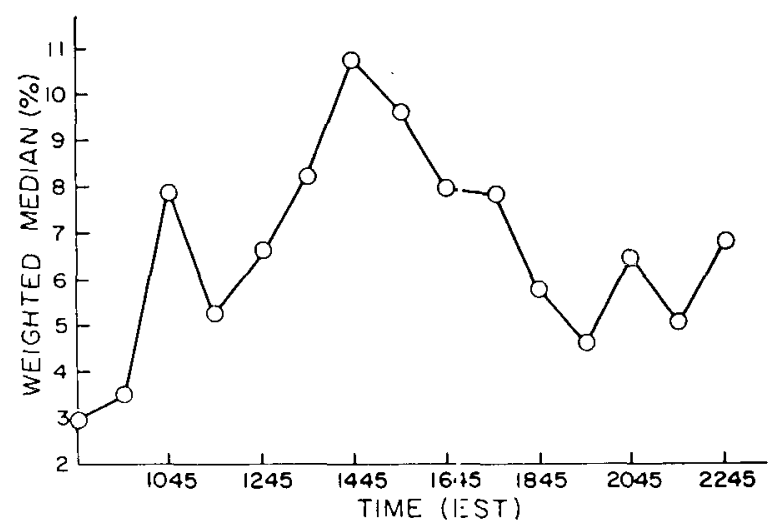

FIG. 5. Graphical representation of weighted median as a function of time. 


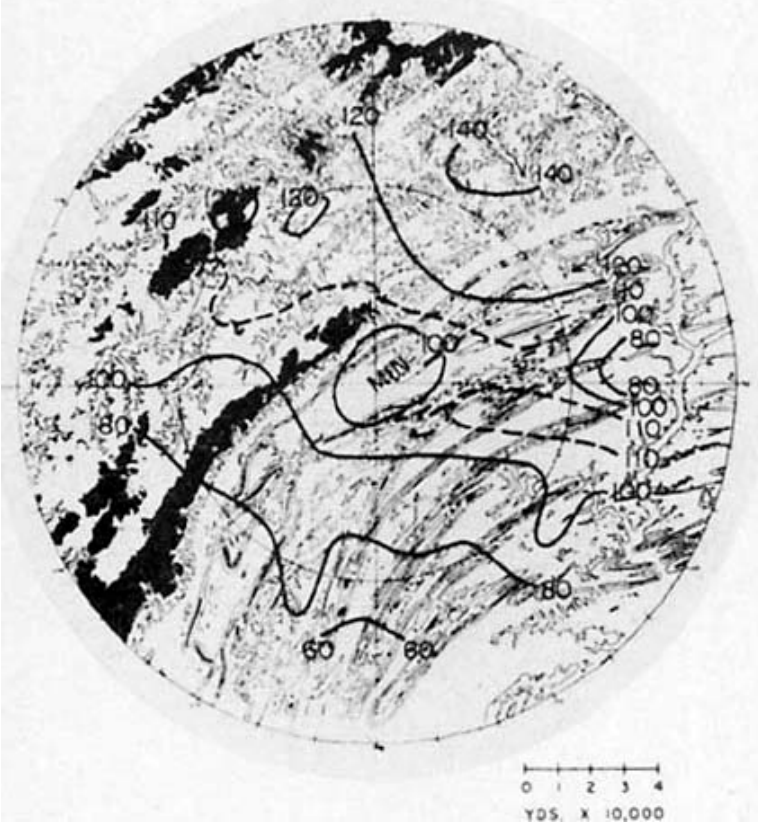

FIG. 6. Mean range normalized echo distribution for period May to September (712 cases).

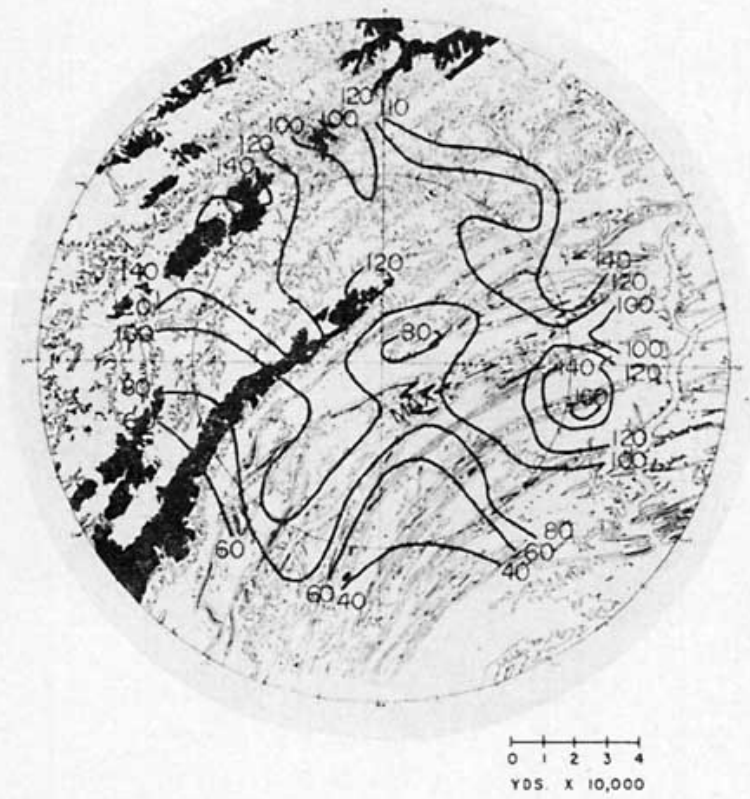

Fig. 8. Mean range normalized echo distribution for 1045 EST (50 cases).

pattern but with slowly decreasing contrast persists into the early afternoon; after 1245 EST the contrast decreases rapidly and the pattern of precipitation becomes more uniform.

The differential between the maxima over the Allegheny Mountains and highland complex and the mini-

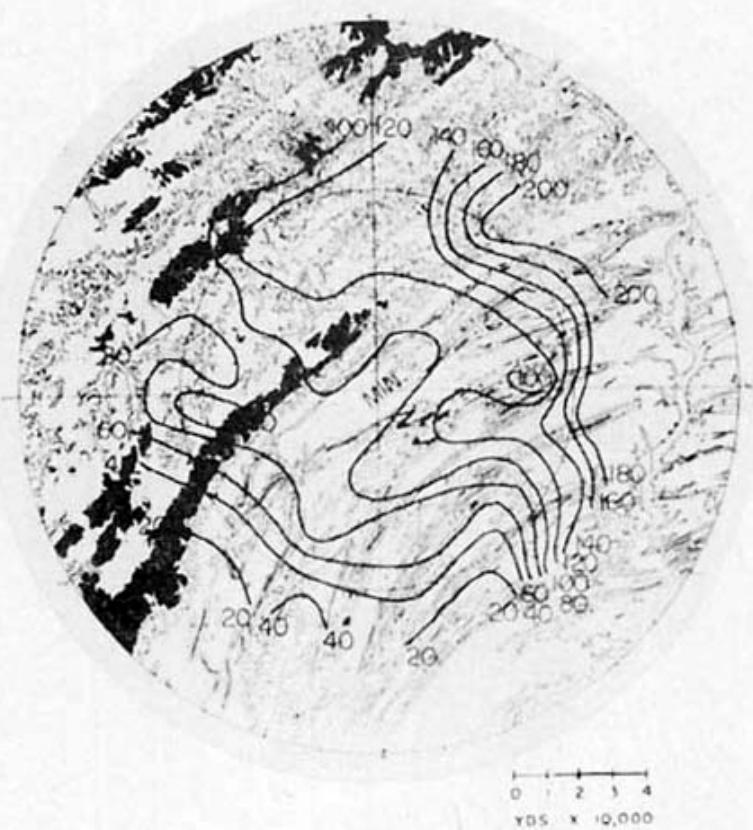

Fıg. 7. Mean range normalized echo distribution for 0945 EST (34 cases).

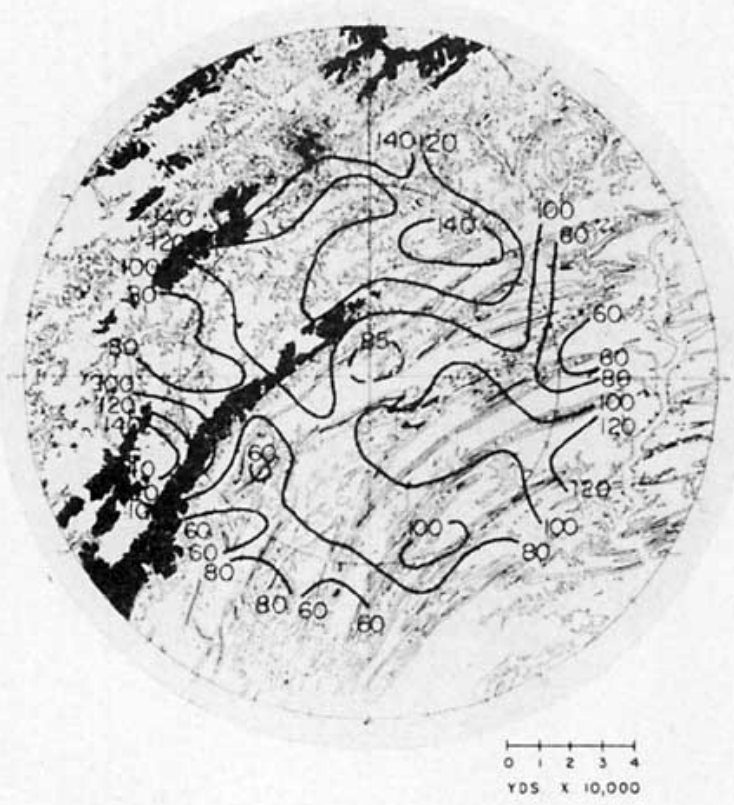

FIG. 9. Mean range normalized echo distribution for 1145 EST (56 cases). mum over the lowland area between them is almost certainly more pronounced than shown. Because the maxima occur at approximately the same range, the magnitudes of both are reduced as a result of the inefficacious property of the range normalization procedure discussed previously. Also, the normalization 


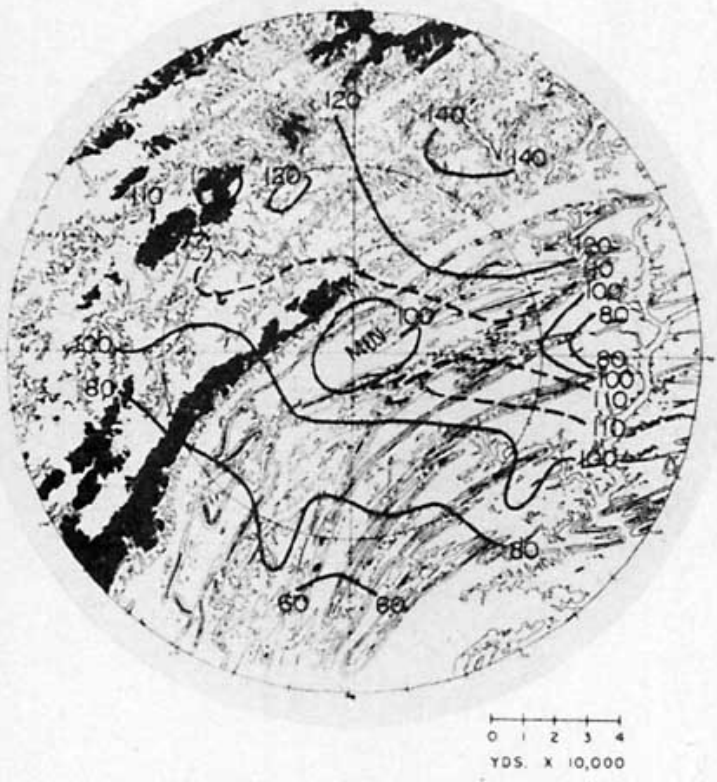

FIG. 10. Mean range normalized echo distribution for 1245 EST (60 cases).

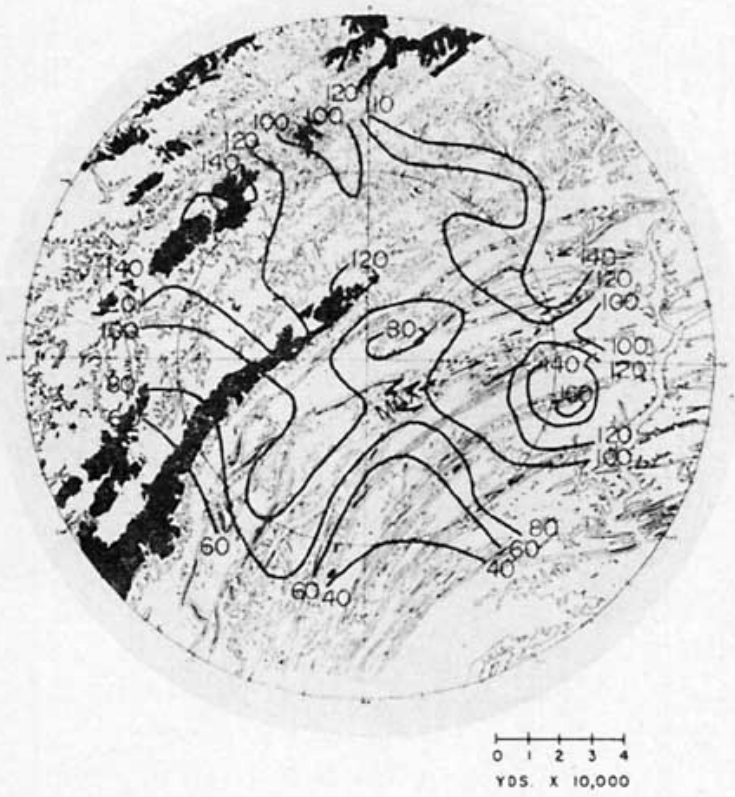

Fig. 12. Mean echo coverage (in per cent) for $1445 \operatorname{EST}(77$ cases).

technique assumes detection capabilities are constant between the center of the scope and the circle of maximum echo occurrence, but in reality detection probably decreases somewhat even very close to the radar.

Because of these limitations, the late afternoon and evening range normalized patterns lack some important features; therefore, non-normalized distributions are

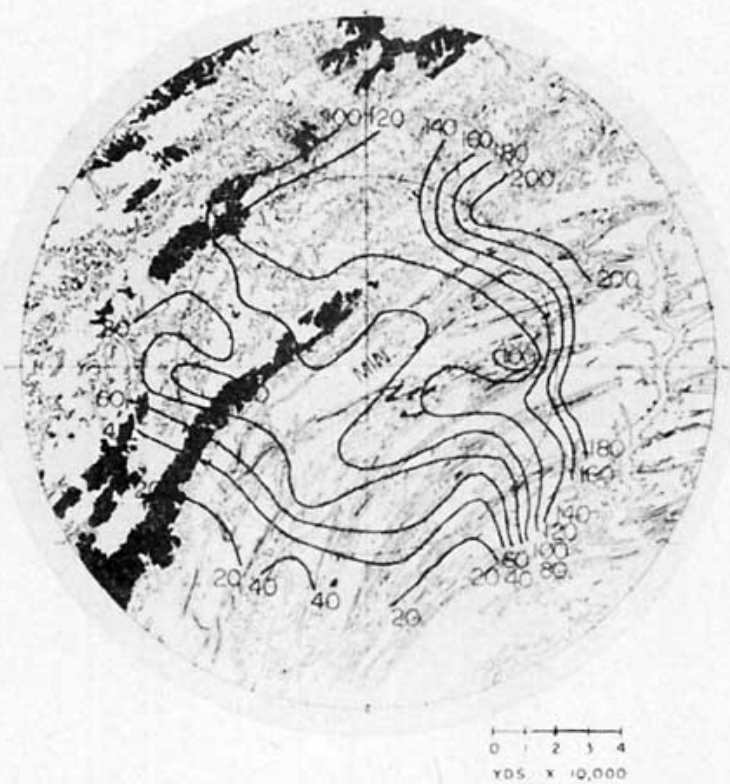

FIG. 11. Mean range normalized echo distribution for 1345 EST (72 cases).

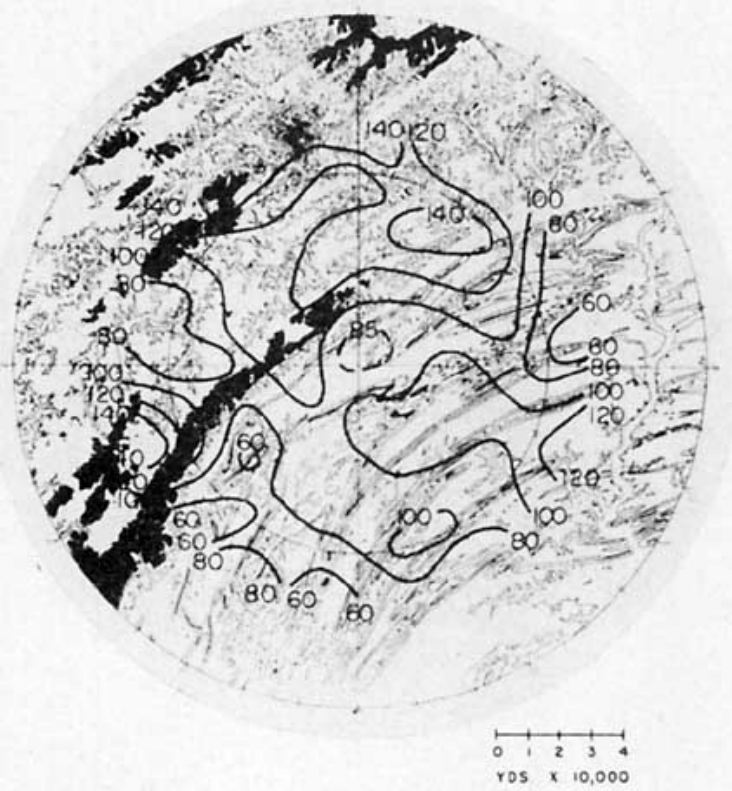

FIG. 13. Mean echo coverage (in per cent) for $1745 \mathrm{ES} \Gamma$ (69 cases)

presented here. In comparing Firs. 12 and 13, it is seen that the areas of maximum echo occurrence again become localized over the high terrain in late afternoon. A very pronounced echo maximum develops to the northwest of the radar at 2145 EiST (Fig. 14) and moves east and southeast at about 20 to $25 \mathrm{mph}$ during the following hour (Fig. 15). 


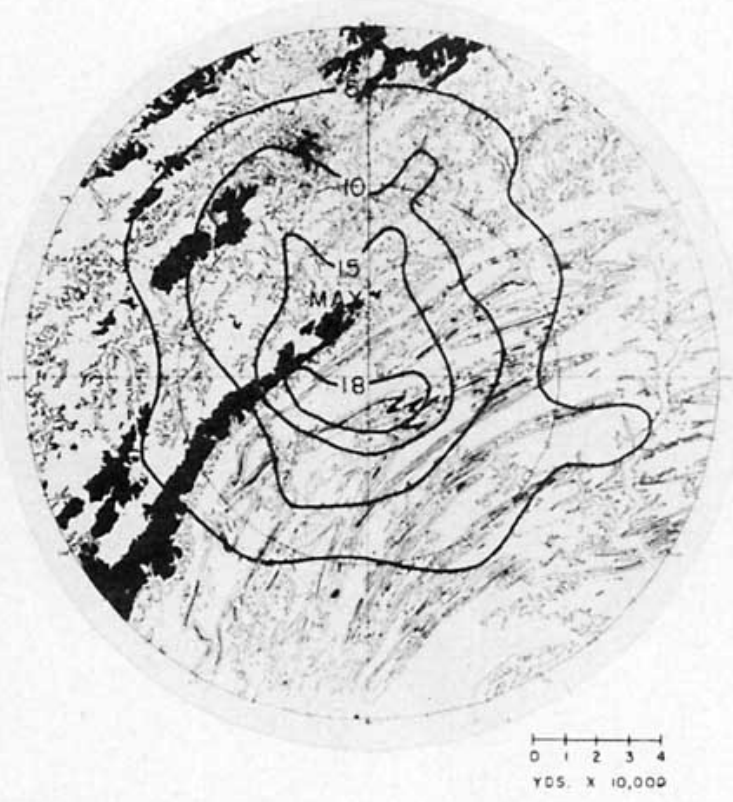

FIG. 14. Mean echo coverage (in per cent) for $2145 \mathrm{EST}$ (34 cases).

\section{Topographic influences}

The semi-diurnal variation of the echo pattern discussed above leaves no doubt that the topography influences convection. Field observations suggest this effect takes the form of a complex thermal-dynamic system, which is a combination of orographically induced gravity waves and thermally produced circulations.

The orientation and configuration of Bald Eagle Valley appear to be quite favorable to development of a cross-valley wind in mid-morning. The northeastsouthwest orientation of the valley and the steepness of the southeast side prevent the sun from heating the southeast slope until late morning. This allows the temperature contrast between valley sides to grow through the early morning, and theoretical studies by Gleeson (1951) suggest the cross-valley wind arising in response to this thermal field should achieve its greatest velocity at $1030 \mathrm{EST}$.

Balloon observations have confirmed the existence of cross-valley flow as well as upslope motion, similar to that reported by Braham and Draginis (1960), on the sunlit side. Further evidence for this mechanism, which is apparently responsible for the pronounced midmorning echo maximum over the Allegheny Mountains, is provided by Hosler, Davis and Booker. ${ }^{1}$ They have shown that well-developed mountain waves frequently form over the modest terrain of central Pennsylvania. A large semi-diurnal variation in. wave amplitudes has been observed with a maximum near 1000 EST and a lesser maximum at about $1800 \mathrm{EST}$.

Stern and Malkus (1953) have shown that rising air from a heated island acts as a "mountain" which causes streamlines to be deflected upward. Rising air over a

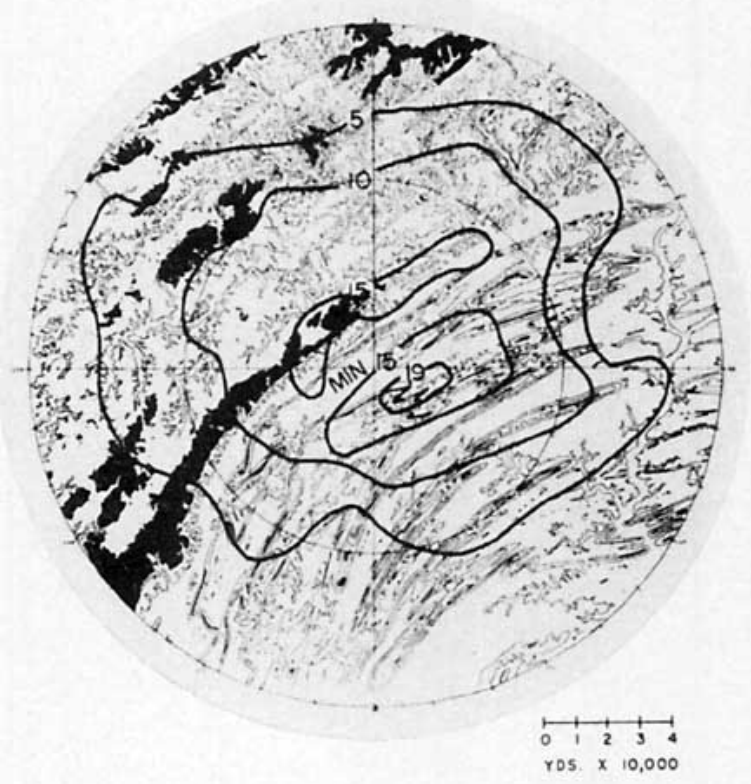

FIG. 15. Mean echo coverage (in per cent) for 2245 EST (25 cases).

ridge probably acts as a barrier in a similar way. Thus, when convection is localized over the mountain ridges, the effective height of the ridges is greatly increased and streamline undulations above the barrier are likewise amplified. This wave in turn further exaggerates the pattern of convection.

Slope and cross-valley winds together with mountain wave amplitudes diminish around midday as insolation becomes more evenly distributed and the height of the mixing layer increases. This reduces the modifying effect of the terrain and the pattern of showers becomes more uniform.

Areas of echo maxima again become concentrated over high terrain and mountain wave amplitudes reach a secondary maximum in the late afternoon. These events may be due to either or both of the following:

1) More rapid cooling of valleys than ridges in late afternoon allows the ridges to become high level heat sources and the resultant localization of convection increases the effective height of mountains, thereby creating waves.

2) An increase of stability precedes the decrease of surface wind, thereby enhancing conditions required for lee waves. Vertical velocity fields associated with the waves favor convection over ridges and subsidence over valleys.

\section{Relations between synoptic variables and scope coverage}

Linear correlation coefficients between the normalized distribution of scope coverage and various synoptic variables are presented in Table 1. On the assumption 
that radar observations taken five hours apart are independent and each upper air sounding is independent, it is calculated that correlation coefficients greater than 0.15 are significant on the 5 per cent level.

The highest correlation coefficient is between the surface dew-point depression and scope coverage. Davis and Entriken (1961) found a very significant correlation coefficient of -0.81 between shower duration and dewpoint depression. These results confirm the importance of low-level moisture in shower development and survival. High dew-point depressions mean air must undergo considerable lifting before condensation can be achieved; therefore a convective column has a small chance of generating a shower. Also the ability of entrainment to limit convection increases with increasing dryness of the air. These effects are well demonstrated by the small scope coverages associated with large dewpoint depressions. The very small dew-point depressions are mostly associated with frontal situations, and the corresponding scope coverage is usually great.

A smaller, but still significant, correlation coefficient was obtained between the $850-\mathrm{mb}$ relative humidity and scope coverage.

Although the $500-\mathrm{mb}$ vorticity is significantly correlated with PPI coverage, the significance of the relation between NWP vertical velocity and scope coverage is questionable. Intuitively, one would expect scope coverage to be at least as closely related to vertical velocity as vorticity, but because of the rather serious inaccuracy of NWP vertical velocity values and the relatively high accuracy of vorticity computations, one finds the latter to be the better indicator of the areal extent of precipitation.

The significance of vertical wind shear is probably a result of three factors. First, frontal situations and their accompanying large scope coverage are often associated with strong wind shear. Second, while strong shear is often damaging to small showers it apparently enhances the development of large cumulonimbus and squall line activity. Finally, the very wide vertical beam width of the M33 radar causes echoes at moderate and long ranges to appear much larger than the horizontal cross-section of the rain-core when shear is present. Leach and Ligda ${ }^{2}$ found that wind shear could elongate a shower several miles in $30 \mathrm{~min}$, the approximate lifetime of an average cell.

${ }^{2}$ Leach, W., and M. G. Ligda, 1957: Convective cell bands in the Central and Eastern United States as observed by radar. Report No. 2 for AF19(604)-1564 Texas A\&M, College Station, Texas, $47 \mathrm{pp}$.
The correlation coefficient between precipitable water and scope coverage is far from siçnificant, but there appears to be a tendency for high amounts of precipitable water and large amounts of sccipe coverage to occur simultaneously.

The joint frequency distributions indicate that the relations between scope coverag, and certain synoptic variables are definitely non-linear; therefore, the coefficients of linear correlation are probably underestimating these relations.

The lack of adequate upper air measurements greatly handicapped attempts to find better relationships between certain synoptic variables and the amount and distribution of precipitation echoes. The most representative radiosonde observatiors available were taken twice daily at Pittsburgh, Pa., which is about $120 \mathrm{mi}$ to the west-southwest of the radar. Obviously such data were not very sensitive to variations in time or space within the radar area.

\section{Relations between scope jatterns and synoptic variables}

Table 2 contains the correlation coefficients between seven synoptic variables and the three scope scattter coefficients for situations when fronts played very little or no role in the production of precipitation. The coefficients which are significant on the 5 per cent level have been underlined.

The structure of convective precipitation is greatly dependent on the low-level moisture supply, since the size and degree of developmer.t and organization of showers and squall lines is negatively correlated with the surface dew-point depression. The correlation between contiguity coefficient and $850-\mathrm{mb}$ relative humidity is also significant on the 5 per cent evel.

These results indicate that the amount of low-level moisture regulates the ability of entrainment to dissipate a cloud and destroy its buoyancy. When moisture is abundant, the entrainment of sutside air is apparently less able to diminish a cloud, anit in many cases may increase its mass. Thus showers grow larger and squall lines form more readily when low-level moisture is plentiful.

Large-scale vertical motion, although not significantly correlated with any of the coefficients, appears to exert a certain amount of influence on the size and organization of convective presipitation. Vorticity is negatively correlated with the degree of echo scatter; consequently high values of vcrticity tend to be asso-

TABLE 1. Linear correlation coefficients between scope coverage and synoptic varis.bles. (Significant relations on the 5 per cent level have been underlined.)

\begin{tabular}{ccccccc}
\hline $\begin{array}{l}\text { Dew-point } \\
\text { depression }\end{array}$ & Wind shear & $\begin{array}{c}\text { Showalter } \\
\text { stability index }\end{array}$ & $\begin{array}{c}\text { Precipitable } \\
\text { water }\end{array}$ & $\begin{array}{c}\text { Vertical } \\
\text { velocity }\end{array}$ & $\begin{array}{c}500 \cdot \mathrm{mb} \\
\text { vorticity }\end{array}$ \\
\hline-0.377 & $\underline{0.169}$ & 0.098 & 0.044 & 0.144 & $\underline{0.25}$ & 0.241 \\
\hline
\end{tabular}


TABLE 2. Correlation coefficients between synoptic parameters and scope scatter coefficients.

(Significant relations on the 5 per cent level have been underlined.)

\begin{tabular}{lcccccrr}
\hline & $\begin{array}{c}\text { Dew-point } \\
\text { depression }\end{array}$ & Wind shear & $\begin{array}{c}\text { Showalter } \\
\text { stability index }\end{array}$ & $\begin{array}{c}\text { Precipitable } \\
\text { water }\end{array}$ & $\begin{array}{c}\text { Vertical } \\
\text { velocity }\end{array}$ & $\begin{array}{c}500 \text {-mb } \\
\text { vorticity }\end{array}$ & $\begin{array}{c}850 \text {-mb relative } \\
\text { humidity }\end{array}$ \\
\hline Contiguity coefficient & -0.41 & 0.09 & 0.05 & 0.07 & 0.14 & 0.06 & 0.22 \\
Scope scatter coefficient & $\underline{0.18}$ & -0.02 & -0.03 & 0.09 & -0.13 & -0.17 & $-\overline{0.03}$ \\
Localized scatter coefficient & $\underline{0.19}$ & 0.03 & 0.07 & -0.07 & -0.14 & -0.06 & -0.08 \\
\hline
\end{tabular}

ciated with well-organized echo patterns. This suggests that the superimposition of a favorable field of vertical motion on a region of convective precipitation will not only tend to increase the area covered with showers, but will allow showers and squall lines to undergo greater development than would otherwise be the case.

\section{Concluding remarks}

As suggested previously, mountain waves and local circulation systems appear to exercise a certain amount of influence on the pattern of convection in central Pennsylvania. The former have been studied extensively with the aid of radar-tracked balloons and aircraft, but the structure and importance of local hot spots and attendant wind systems are not definitely known and must be inferred mainly from radar data. A better interpretation of these data would undoubtedly be possible if the nature of local winds and heat sources were documented by extensive field experiment.

Acknowledgments. The author wishes to extend his sincere appreciation to Dr. Charles L. Hosler for his helpful suggestions and stimulating discussion during the preparation of this paper. The author is also grateful to Dr. Alfred K. Blackadar and Larry G. Davis for their cooperation and suggestions, and to Dr. Robert $\mathrm{T}$. Duquet for his aid in programming.

\section{REFERENCES}

Austin, P. M., 1957: Distribution of precipitation echoes as observed by radar at Cambridge, Massachusetts. Proc. Sixth Weather Radar Conf., Boston, Amer. Meteor. Soc., 221-226.

Battan, L. J., and R. R. Braham, Jr., 1956: A study of convective precipitation based on cloud and radar observations. $J$. Meteor., 13, 587-591.
Beckwith, W. B., 1958: Shower and thunderstorm echo patterns in Eastern Colorado. Proc. Seventh Weather Radar Conf., Boston, Amer. Meteor. Soc., 51-57.

Braham, Jr., R. R., 1958: Cumulus cloud precipitation as revealed by radar-Arizona, 1955. J. Meteor., 15, 75-83.

—_ and M. Draginis, 1960: Roots of orographic cumuli. $J$. Meteor., 17, 214-222.

Bruckner, W., 1951: Weather observations in Columbia. Weather, 6, 54-58.

Byers, H. R., and L. J. Battan, 1949: Some effects of vertical wind shear on thunderstorm structure. Bull. Amer. meteor. Soc., 30, 168-175.

Byers, H. R., and R. R. Braham, 1949: The thunderstorm. Washington, U.S. Government Printing Office, $287 \mathrm{pp}$.

Clark, R. A., 1960: A study of convective precipitation as revealed by radar observations, Texas 1958-59. J. Meteor., 17, 415425.

Cox, M. K., 1959: The distribution and variability of cold-front precipitation. Bull. Amer. meteor. Soc., 40, 477-480.

Davis, L. G., and H. Entriken, 1961: The duration of convective echoes. Proc. Ninth Weather Radar Conf., Boston, Amer. Meteor. Soc., 50-55.

Gleeson, T. A., 1951: On the theory of cross-valley winds arising from differential heating of the slopes. J. Meteor., 8, 398-405.

$\ldots, 1953$ : Effects of various factors on valley winds. J. Meteor., $10,262-269$.

Laws, J. O., and D. A. Parsons, 1943: The relation of raindrop size to intensity. Trans. Amer. geophys. Union, 24, 124-138.

Ludlam, F. H., and R. S. Scorer, 1953: Convection in the atmosphere. Quart. $J . R$ meteor. Soc., 79, 317-340.

Mather, J. R., 1949: An investigation of the dimensions of precipitation echoes by radar. Bull. Amer. meteor. Soc., 30, $271-$ 277.

Richards, W. J., 1953: The frequency of radar storm echoes as a function of position. Proc. Conf. Radio Meteor., Univ. of Texas, Austin.

Riggs, L. P., and L. E. Truppi, 1957: A survey of radar climatology. Proc. Sixth Weather Radar Conf., Boston, Amer. Meteor. Soc., 227-232.

Stern, M. E., and J. S. Malkus, 1953: The flow of a stable atmosphere over a heated island, Part II. J. Meteor., 10, 105-120. 